\title{
T Tubes in Intestinal Perforations in Children
}

\author{
H. Ramesh · M. Sharma
}

Published online: 20 February 2009

(c) Société Internationale de Chirurgie 2009

We read with interest the article by Pandey et al. [1] which highlighted the possible benefit of $\mathrm{T}$ tubes in the treatment of children with multiple typhoid perforations and a poor general condition. We agree that the idea is a promising one, especially because it includes fixation of the proximal perforation to the parietes. It is likely that this step contributes more to the healing than placement of the $T$ tube itself, and the same effect could be achieved even with a straight tube. This is especially significant because the authors recommend removal of the tube by the end of the second week, at which time some patients are still suffering from the effects of peritoneal sepsis. If removal is delayed, the PVC tube may stiffen and removal could be traumatic. However, we have the following concerns:

1. That the procedure has been compared with primary closure when in fact it would have been appropriate to compare it with ileostomy, which is really an extension of the T-tube technique and the procedure most applicable to the clinical situation.
2. In patients with considerable peritoneal contamination and friable tissue, the parietal fixation may not heal and the patient could suffer more leakage of intestinal contents into the peritoneal cavity, an observation which might be seen if more patients had been studied.

3. The operative picture suggests that a polyvinyl chloride $\mathrm{T}$ tube was used. May we venture to suggest that a red rubber $\mathrm{T}$ tube may prove advantageous, especially as it promotes greater tissue reaction and adhesion to the parietal wall and is not likely to stiffen should removal be delayed for any reason.

\section{Reference}

1. Pandey A, Kumar V, Gangopadhyay AN et al (2008) A pilot study on the role of T-Tube in typhoid ileal perforation in children. World J Surg 32:2607-2611
H. Ramesh $(\bowtie) \cdot$ M. Sharma

Department of Surgical Gastroenterology, Lakeshore Hospital \& Research Center, Cochin 682304, Kerala, India

e-mail: hramesh@vsnl.com 